\title{
RIQUEZA DE GALHAS ENTOMÓGENAS EM ÁREAS ANTROPIZADAS E PRESERVADAS DE CAATINGA ${ }^{1}$
}

Sheila Patricia Carvalho-Fernandes ${ }^{2}$, Jarcilene Silva de Almeida-Cortez ${ }^{3}$ e Andre Luiz Nunes Ferreira ${ }^{4}$

\begin{abstract}
RESUMO - Insetos indutores de galhas, também denominados cecidógenos, são considerados mais especializados por possuírem interação direta com tecidos internos da planta, modificando-os em seu benefício e tornando-se mais dependentes da espécie hospedeira. Este estudo investigou a fauna de insetos galhadores em espécies hospedeiras da Caatinga, em ambientes com diferentes intensidades de ação antrópica. As áreas foram selecionadas de acordo com uma escala de sucessão ecológica (preservadas, intermediárias e antropizadas), sendo três réplicas de cada, totalizando nove áreas. Em cada área foram amostradas oito parcelas de $10 \mathrm{~m}^{2}$ cada, distanciadas $10 \mathrm{~m}$ entre si. Foram encontrados 25 morfotipos de galhas distribuídos em 18 espécies hospedeiras pertencentes a oito famílias vegetais. Fabaceae foi a família com maior riqueza de galhas, com seis morfotipos, sendo Caesalpinia pyramidalis Tul. a espécie com maior número de galhas, com quatro morfotipos. Em relação aos órgãos atacados, $68 \%$ das galhas ocorreram em folhas, $28 \%$ em ramos e $4 \%$ em botões florais. A maioria das galhas encontradas ocorreu isoladamente (84\%), glabra (56\%) e de formas esféricas (32\%), amorfas (28\%), discoides (12\%) e globoides (12\%). No estrato arbóreo foi encontrada a maior riqueza de galhas, com 16 morfotipos, seguido do estrato arbustivo e herbáceo, respectivamente com sete e dois morfotipos. A riqueza de galhas sofreu influência do grau de conservação das áreas, e houve diferenças entre os ambientes preservados e antropizados.
\end{abstract}

Palavras-chave: Impacto ambiental, Bioindicadores e Herbivoria.

\section{THE INSECT GALL RICHNESS IN PRESERVED AND ANTHROPIC AREAS OF CAATINGA}

\begin{abstract}
Gall-inducing insects, also called cecidogens, are regarded as more specialized because they present direct interaction with internal tissues of the plant, modifying them in its benefit and because of that, becoming more dependent of the host species. The present study investigated the fauna of gall-inducing insects in plants from environments with different intensities of anthropic action in the Caatinga. The areas were selected according to an ecological succession scale (preserved, intermediate and anthropic areas), with three replicates each, totaling nine areas. Eight $10 \mathrm{~m}^{2}$ plots were sampled in each area, separated by an interval of $10 \mathrm{~m}$. It was found 25 morphotypes of galls in 18 host species of eight plant families. The family Fabaceae bears the largest number of morph-species of gall, with six morphotypes and Caesalpinia pyramidalis Tul. presents four morphotypes. The majority of galls was found on leaves (68\%) followed by stems (28\%) and bud flowers (4\%). The galls occurred isolated (84\%), glabrous (56\%), most are spherical (32\%), amorf (28\%), discoids (12\%) and globoids (12\%). The greatest richness of galls was found in the tree layer, with sixteen morphotypes followed by shrub (7) and herbaceous (2). The richness of galls was influenced by the degree of conservation of the studies areas. There were differences between the preserved and anthropic areas.
\end{abstract}

Keywords: Environment impact, Bioindicator and Herbivory.

\footnotetext{
${ }^{1}$ Recebido em 01.09.2009 e aceito para publicação em 22.03.2012.

${ }^{2}$ Programa de Pós-Graduação em Zoologia pelo Museu Nacional-UFRJ, MN-UFRJ, Brasil. E-mail: <sheilapcfernandes@gmail.com> .

${ }^{3}$ Universidade Federal de Pernambuco, Centro de Ciências Biológicas, Departamento de Botânica. E-mail: <jacortez@ufpe.br> .

${ }^{4}$ Doutorado em Engenharia Civil pela Universidade Federal de Pernambuco, UFPE, Brasil. E-mail: <andrelunufe@gmail.com>.
} 


\section{INTRODUÇÃO}

A exploração das plantas hospedeiras por insetos herbívoros ocorre quando eles se alimentam externamente, sugando a seiva do sistema vascular, quando escavam o interior de seus órgãos ou, ainda, formando galhas (STRONG et al., 1984). Insetos indutores de galhas, também chamados de cecidógenos, são considerados mais especializados por possuírem interação direta com tecidos internos da planta, modificando-os em seu benefício e tornando-se mais dependentes da espécie hospedeira. Os formadores de galhas encontram nas plantas fonte de alimento e proteção contra fatores bióticos e abióticos (FERNANDES; PRICE, 1988).

A interação entre o inseto galhador e sua planta hospedeira é considerada uma das mais complexas associações, pois cada espécie de inseto induz galhas que são fisiológica e morfologicamente diferentes de outras espécies, possuindo diferenciação celular distinta daquela encontrada em tecidos vegetais não galhados (SHORTHOUSE et al., 2005).

A região Nordeste encontra-se dentre as menos estudadas quando nos referimos às galhas induzidas por insetos. Estudos pontuais envolvendo aspectos biológicos e ecológicos entre insetos galhadores e espécies vegetais foram realizados por Almeida-Cortez et al. (2006), Silva e Almeida-Cortez (2006), SantosMendonça et al. (2007) e Lebel et al. (2008), principalmente em áreas de Floresta Atlântica. O primeiro levantamento foi realizado por Fernandes et al. (2009) que vistoriaram galhas entomógenas no Parque Estadual de Dois Irmãos, um fragmento urbano de Mata Atlântica em Recife, Pernambuco.

O conhecimento sobre a interação galhador-planta hospedeira na Caatinga ainda é escasso. Embora a Caatinga se estenda em nove estados brasileiros e possua um alto grau de endemismo, várias destas espécies de animais e plantas foram descritas recentemente para a região, indicando um conhecimento zoobotânico bastante precário e recente quando comparado a outros ecossistemas (LEAL et al., 2003).

A maioria dos insetos utilizados como bioindicadores (LEAL, 2003; FREITAS et al., 2006) não corresponde à fauna de galhadores. Os insetos indutores de galhas fazem parte de uma guilda com características de potenciais indicadores da qualidade do habitat, tais como: serem sésseis e de fácil localização, possuírem relação interespecífica com a planta hospedeira, serem abundantes e, em sua maioria, com permanência das galhas nas plantas mesmo após a saída do indutor (FERNANDES et al., 1995).

Apesar das características citadas, poucos estudos têm utilizado insetos galhadores como indicadores da qualidade do habitat. Fernandes et al. (1995) utilizaram insetos galhadores na comparação de habitats secos e úmidos e encontraram uma maior riqueza de insetos galhadores em ambientes estressados higrotermicamente. Por outro lado, Julião et al. (2005) não encontraram diferenças na riqueza de galhas entre habitats que variavam entre áreas em ambientes urbanos até áreas rurais.

O presente estudo investigou a fauna de insetos galhadores em espécies hospedeiras da Caatinga em áreas com diferentes intensidades de ação antrópica.

\section{MATERIAL E MÉTODOS}

O estudo foi realizado em áreas de Caatinga, próximas à Usina Hidroelétrica de Xingó pertencente à Companhia Hidroelétrica do São Francisco (CHESF). As áreas estavam situadas em fazendas particulares e limites da CHESF localizadas nos municípios Olho d’Água do Casado (Alagoas), Canindé de São Francisco (Sergipe) e Paulo Afonso (Bahia). O clima da região é semi-árido quente, caracterizado por precipitação escassa (500 - 600 mm) e irregular, o que determina um longo período de seca. As temperaturas médias anuais são de 25 a $27^{\circ} \mathrm{C}$ nos meses mais quentes, caindo para menos de $21^{\circ} \mathrm{C}$ nos meses mais frios, ao longo do Rio São Francisco.

As coletas foram realizadas em ambientes com diferentes estados de conservação de acordo com uma escala de sucessão ecológica, classificados em: preservado, intermediário e antropizado. Para cada ambiente foram selecionadas três áreas que constituíram as réplicas do estudo (Figura 1). As áreas foram caracterizadas como preservadas quando ausentes de exploração há pelo menos 30 anos; intermediárias quando exploradas há 15 anos; e antropizadas, quando se encontravam sob pressão antrópica constante, tais como pasto, cultivo ou locais de passagem de torres de energia elétrica. Em cada área foram amostradas oito parcelas de $10 \mathrm{~m}^{2}$ cada, distanciadas $10 \mathrm{~m}$ entre si, perfazendo um total de 24 parcelas por ambiente. 


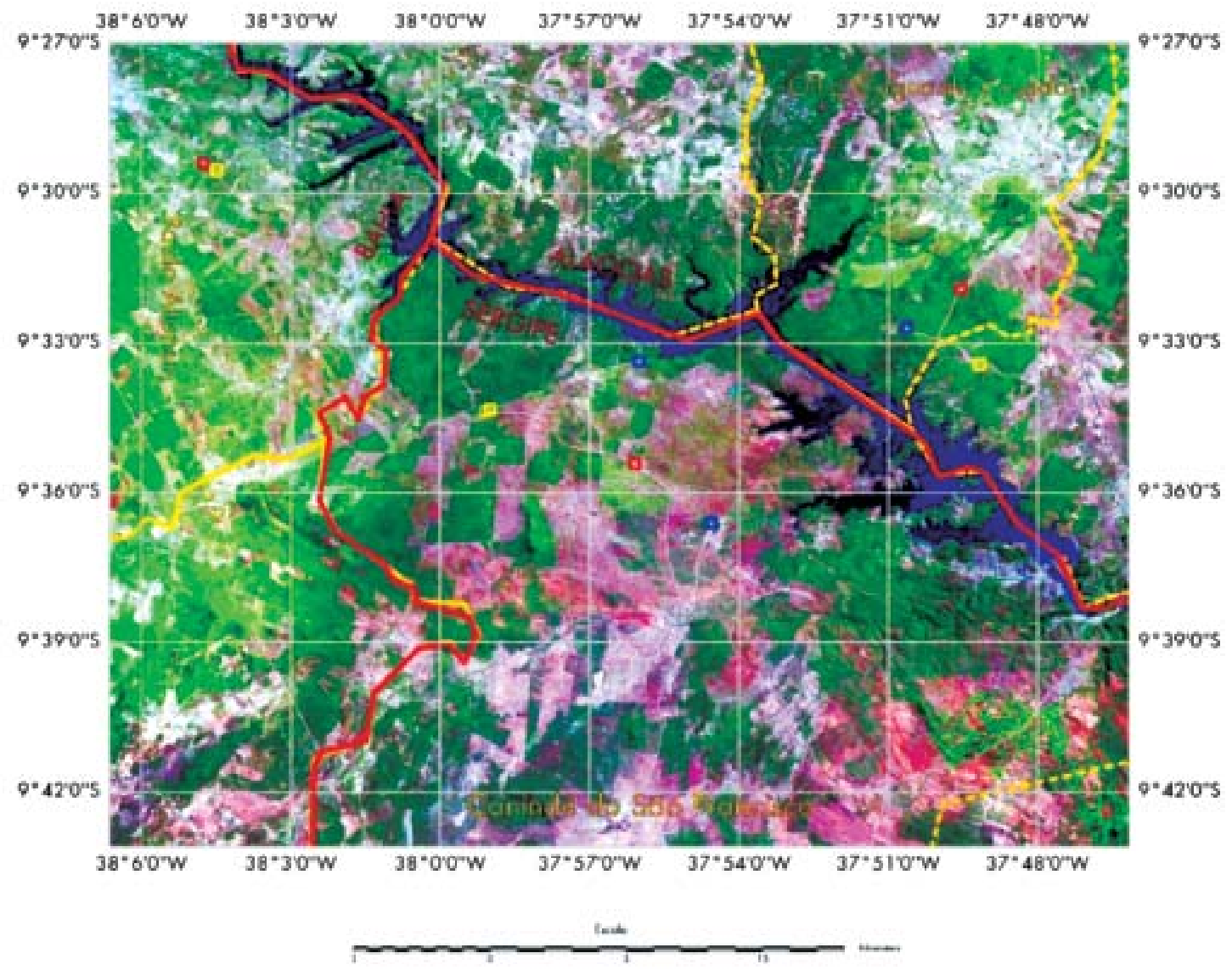

Figura 1 - Localização geográfica da área de estudo na região de Xingó, Estados de Alagoas, Sergipe e Bahia, Brasil, com diferentes graus de preservação: áreas preservadas: azul, intermediárias: amarelo e antropizadas: vermelho.

Figure 1 - Geographical location of studied areas in Xingó, states of Alagoas, Sergipe and Bahia, Brazil, with different preservation levels: Preserved areas - blue; intermediate areas - yellow; and anthropic areas - red.

As coletas foram realizadas mensalmente de agosto de 2005 a abril de 2006. Em cada parcela todas as plantas encontradas foram vistoriadas à procura de galhas em suas partes aéreas.

As galhas presentes em cada parcela em estudo foram registradas e levadas ao Laboratório de Interação Planta-Animal da Universidade Federal de Pernambuco, onde as cecídias foram fotografadas, descritas morfologicamente e acondicionadas em potes plásticos para emergência dos insetos indutores e da fauna associada. As plantas hospedeiras foram herborizadas para posterior identificação.

A riqueza de galhas foi comparada entre os três estágios de conservação dos ambientes (tratamentos), em delineamento estatístico de blocos ao acaso com três blocos (áreas/ambiente) e oito repetições por bloco, através da análise de variância (ANOVA) e as médias comparadas, a posteriori, pelo teste de Tukey ao nível de 5\% de probabilidade (ZAR, 1999).

\section{RESULTADOS}

Foram encontrados 25 morfotipos de galhas distribuídos em 18 espécies hospedeiras pertencentes a oito famílias vegetais (Tabela 1 ). Fabaceae foi a família com maior riqueza de galhas, com onze morfotipos, sendo Caesalpinia pyramidalis Tul. a espécie com maior número de espécies de insetos galhadores, com quatro morfotipos.

Revista Árvore, Viçosa-MG, v.36, n.2, p.269-277, 2012 


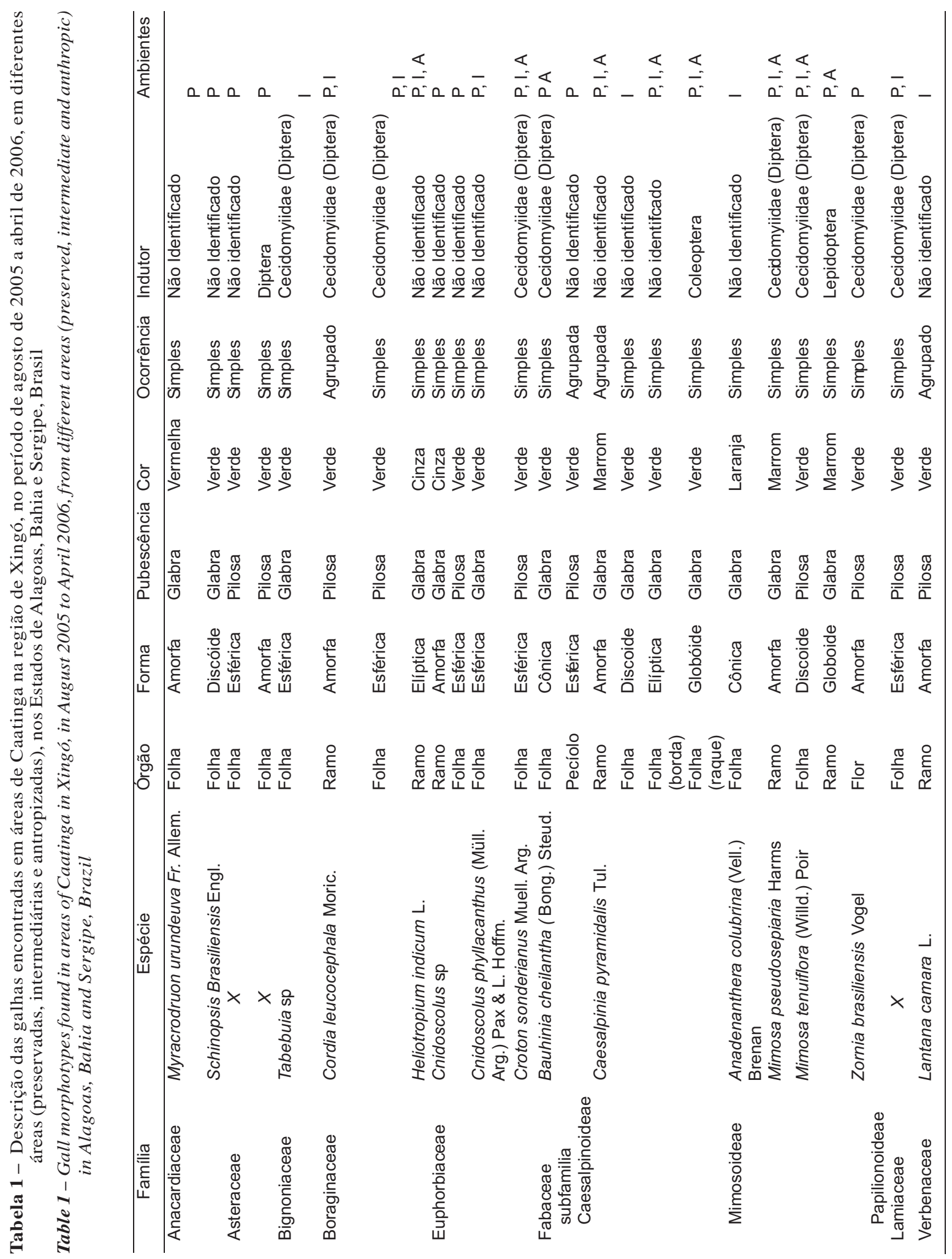


Em relação aos órgãos atacados, 68\% das galhas ocorreram nas folhas (Figura 2), 28\% em ramos (Figura 3) e 4\% em botões florais. A maioria das galhas encontradas apresentou a forma esférica (32\%) (Figura 4), 28\% não possuíram forma definida (Figuras 5 e 6), discóides e globóides representaram $12 \%$ cada e as formas elíptica e cônica juntas totalizaram 16\%. A maioria das galhas ocorreu isoladamente (84\%) e não apresentaram pilosidade (56\%) (Figura 7). No estrato arbóreo foi encontrada a maior riqueza de galhas, com 16 morfotipos, seguido do estrato arbustivo e herbáceo com sete e dois morfotipos, respectivamente.

A espécie vegetal com maior abundância de galhas foi Anadenanthera colubrina (Vell.) Brenan (Fabaceae, subfamília Mimosoideae) (Figura 8), com uma média de 24 galhas por folha. Porém a abundância de galhas foliares para a maioria das espécies não ultrapassou a média de três galhas por órgão afetado. Galhas caulinares não ocorreram em grandes quantidades, sendo raro encontrar mais de uma galha em cada ramo.

Dentre os insetos indutores, 10 morfotipos foram induzidos pela ordem Diptera (Figura 9). Coleoptera e Lepidoptera induziram um morfotipo de galha cada. Os Hymenoptera e Coleoptera compuseram a entomofauna associada às galhas, sendo estes insetos encontrados em seis e três morfotipos, respectivamente. Além de insetos, foi registrada a ocorrência da ordem Pseudoescorpiones como inquilinos em galhas no ramo de C. pyramidalis.

A maior riqueza de galhas foi encontrada nas áreas preservadas $(n=21)$ seguida das áreas intermediárias $(n=15)$ e antropizadas $(n=8)$. A riqueza de galhas sofreu influência do grau de conservação das áreas ( $F=10,5$; g.l = 2; $\mathrm{p}<0,05)$. Houve diferenças entre as áreas preservadas e antropizadas $(Q=5,23$; $\mathrm{p}<0,05$ ), porém as diferenças na riqueza de galhas entre estas áreas e as intermediárias não foram significativas.

Nas áreas preservadas as galhas ocorreram em 15 espécies vegetais, sendo que do total de morfotipos encontrados, sete foram exclusivos dessas áreas. Nas áreas intermediárias 10 espécies vegetais foram hospedeiras de galhas, com quatro morfotipos registrados unicamente nesses ambientes. Já as galhas das áreas antropizadas encontraram-se distribuídas em cinco espécies de plantas hospedeiras, porém nenhum morfotipo foi exclusivo dessas áreas.

\section{DISCUSSÃO}

Esse é o primeiro estudo de galhas induzidas por insetos em áreas de Caatinga, na região de Xingó. Houve destaque das plantas da família Fabaceae como hospedeiras de galhas, representadas por espécies das subfamílias Caesalpinoideae, Mimosoideae e Papilionoideae, totalizando 44\% $(n=11)$ do total de galhas encontradas. Estas subfamílias vegetais possuem grande representatividade na composição florística do semi-árido do nordeste brasileiro (SAMPAIO, 1995, 2002; RODAL et al., 1999). Já Fernandes et al. (1988) verificaram que as espécies de Fabaceae se destacaram em número de espécies hospedeiras de galhas e número de morfotipos de galhas por espécie em vegetação de Cerrado. Gonçalves-Alvim e Fernandes (2001) e Maia e Fernandes (2004) também em vegetação de cerrado, e Julião et al. (2002) em estudo no Pantanal, obtiveram resultados semelhantes.

Os órgãos mais afetados foram as folhas em suas diversas partes, seguida dos ramos e flores. Este resultado corrobora levantamentos realizados em diversos ecossistemas no Brasil (JULIÃO et al., 2002; MAIA e FERNANDES, 2004; OLIVEIRA e MAIA, 2005; MAIA et al., 2008; FERNANDES et al., 2009 ).

A maioria das galhas foi encontrada no estrato arbóreo. Devido ao longo período de seca observado na Caatinga, as ervas desaparecem, os arbustos perdem totalmente as folhas nesta época e apenas algumas árvores permanecem com as folhas. Julião et al. (2002) também encontraram maior riqueza de galhas no estrato arbóreo, seguido de arbustos e ervas. Na Caatinga, porém, esse estrato se encontra bastante ameaçado, pois compõe as plantas com ramos mais grossos, utilizado como lenha pela população (SILVA; SAMPAIO, 2008).

A ordem Diptera induziu a maioria das galhas das quais foram obtidos os insetos adultos. Essa ordem, representada em sua maioria por espécies de Cecidomyiidae, constitui o maior táxon de insetos galhadores na região Neotropical (FERNANDES et al., 1996). Os Coleoptera e Lepidoptera também encontrados nas áreas apresentaram o mesmo padrão para os demais estudos realizados no Brasil, nos quais essas galhas induzidas por espécies dessas ordens sempre estão presentes, porém possuem riqueza menor que os Diptera (MAIA; FERNANDES, 2004; OLIVEIRA; MAIA, 2005; MAIA et al., 2008). A obtenção de insetos indutores adultos em laboratório é muito difícil, principalmente 

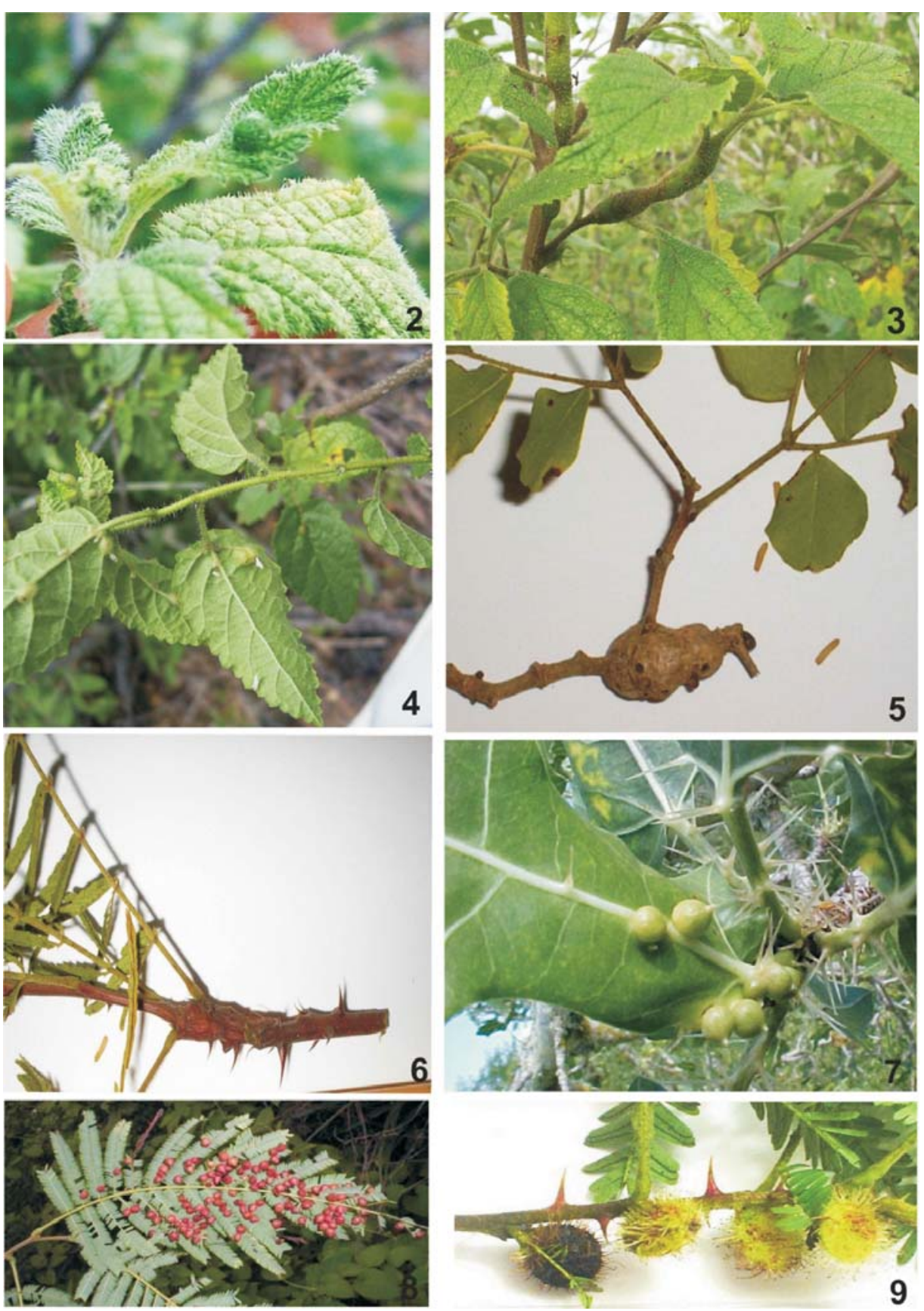

Figuras 2-9 - Galhas encontradas na região de Xingó, Estados de Alagoas, Sergipe e Bahia, Brasil, de agosto de 2005 a abril de 2006. 2. Galha foliar, 3. Galha no ramo e, 4. Galha esférica em Cordia leucocephala; 5. Galha no ramo em Caesalpinia pyramidalis; 6. Galha no ramo em Mimosa tenuiflora; 7. Galha esférica em Cnidoscolus phyllacanthus; 8. Galha cônica em Anadenanthera colubrina e 9. Galha discoide em Mimosa tenuiflora.

Figures 2-9 - Galls found in the region of Xingó, states of Alagoas, Sergipe and Bahia, Brazil, in August 2005 to April 2006. 2. Leaf galls, 3. Stem gallf and 4. Spherical leaf gall on Cordia leucocephala; 5. Stem gall on Caesalpinia pyramidalis; 6. Stem gall on Mimosa tenuiflora; 7. Spherical gall on Cnidoscolus phyllacanthus; 8. Conical gall on Anadenanthera colubrina; 9. Discoid gall on Mimosa tenuiflora.

Revista Árvore, Viçosa-MG, v.36, n.2, p.269-277, 2012 
quando não se conhece a biologia dos insetos galhadores, como ocorre em áreas de Caatinga. Além disso, a escassez de taxonomistas que estudem esses grupos dificulta a identificação específica de tais insetos.

A fauna associada às galhas foi composta por Hymenoptera e Coleoptera. Essas duas ordens são amplamente registradas em galhas, a primeira como parasitóides, sendo o principal fator de mortalidade dos indutores, e a segunda como inquilinos. Em outros ecossistemas, tais como Cerrado e Restinga, essas ordens também já foram registradas com os mesmos hábitos verificados nesse estudo (MAIA, 2001; MAIA; FERNANDES, 2004; MAIA et al., 2008). Maia (2001) registrou pseudoescorpiões predadores do gênero Novohorus em galhas cilíndricas de Eugenia multiflora Cambess. e E. rotundifolia Casar. (Myrtaceae) em restingas do Rio de Janeiro, similar ao estudo no qual foi observado a presença de pseudoescorpião, cuja identificação não foi determinada, em galhas de ramos de C. pyramidalis.

Houve decréscimo da riqueza de espécies vegetais hospedeiras de galhas proporcional ao grau de antropização. Ao comparar a diversidade de galhadores entre biótopos urbanos e rurais Julião et al. (2005) não encontrou diferenças na riqueza de galhadores, porém a abundância desses insetos foi influenciada pela paisagem, sendo as áreas com menos impactos as que apresentaram maiores abundâncias. Segundo Pereira et al. (2003), o número de espécies é influenciado pelo uso prévio da área, com forte redução com o aumento da degradação ambiental.

A relação planta hospedeira - inseto galhador é interespecífica (SHORTHOUSE et al., 2005), por isso, a extinção local de uma espécie vegetal impossibilita a existência de sua fauna associada, neste caso, os galhadores. Várias hipóteses procuram explicar a distribuição dos insetos indutores de galhas em determinados ambientes, como a da riqueza de espécies vegetais. Segundo Fernandes e Price (1988), a riqueza de galhas causada por insetos é influenciada pela riqueza de plantas do habitat. Em Xingó, a perturbação do habitat determinou a composição da vegetação nas áreas e a maior riqueza de galhadores em áreas consideradas preservadas.

Alguns morfotipos de galhas foram encontrados exclusivamente em ambientes preservados. A maior complexidade desses ambientes proporcionada pelo grau de conservação das áreas estudadas ampliou a quantidade de nichos, e desse modo favoreceu a ocorrência de insetos galhadores em tais áreas em Xingó.

Galhas de insetos já estão sendo utilizadas como indicadores da qualidade ambiental. Julião et al. (2005), em estudos com duas espécies vegetais invasoras em habitats com diferentes históricos de uso, encontrou maior riqueza de insetos galhadores associada a Baccharis dracunculifolia em ambientes pouco urbanizados. Os autores também relacionaram a porcentagem de cobertura vegetal dos habitats com a fauna de galhadores e encontraram uma forte e positiva relação entre os dois fatores, resultado similar ao encontrado no presente estudo no qual a riqueza de galhas foi maior em ambientes preservados.

O estudo de insetos galhadores e suas respostas às mudanças ambientais são necessários visto que esses animais são totalmente dependentes de espécies vegetais. Perturbações ambientais que resultam em modificação da vegetação podem provocar a extinção local desses insetos pelo desaparecimento de suas plantas hospedeiras. Dessa forma, a preocupante perda da biodiversidade torna imprescindível o levantamento de informações em áreas de alto endemismo e em acelerado processo de degradação como a Caatinga.

\section{AGRADECIMENTOS}

Ao CNPqpela concessão da bolsa de iniciação científica aos dois primeiros autores e pelo financiamento do projeto Universal (477870) e à CHESF pelo auxílio logístico.

\section{REFERÊNCIAS}

ALMEIDA-CORTEZ, J. S. et al. Nota biológica e novo registro de Prospoliata bicolorata (Coleoptera, Curculionidae, Baridinae) em um fragmento de Mata Atlântica de Pernambuco. Biociências, v.14, n.2, p.228-230., 2006.

FERNANDES, G. W.; PRICE, P. W.

Biogeographical gradients in galling species richness: tests of hypotheses. Oecologia, v.76, n.1, p.161-167., 1988.

FERNANDES, G. W.; TAMEIRÃO-NETO, E.; MARTINS, R. P. Ocorrência e caracterização de galhas entomógenas na vegetação do campus Pampulha da Universidade Federal de Minas Gerais. Revista Brasileira de Zoologia, v. 5, n.1, p.11-29, 1988.

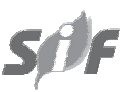

Revista Árvore, Viçosa-MG, v.36, n.2, p.269-277, 2012 
FERNANDES, G. W.; PAULA, A. S.; LOYOLA JR, R.. Distribuição diferencial de insetos galhadores entre habitats e seu possível uso como bioindicadores. Vida Silvestre

Neotropical, v.4, n.2, p.133-139, 1995

FERNANDES, G. W. et al. Galling insects on Neotropical species of Baccharis (Asteraceae). Tropical Zoology, v.9, p.315-332, 1996.

FERNANDES, S. P. C. et al. Galhas entomógenas em um fragmento urbano de Mata Atlântica no Centro de Endemismo de Pernambuco. Revista Brasileira de Biociências, v.7, n.3, p.240244, 2009.

FREITAS, A. V. L. et al. Insetos como indicadores de conservação da paisagem. In: ROCHA, C. F. D. et al. (Eds.) Biologia da conservação: essências. São Carlos: Rima, 2006. v.1. p.357-385.

GONÇALVES-ALVIM, S. J.; FERNANDES, G. W. Biodiversity of galling insects: historical, community and habitat effects in four neotropical savannas. Biodiversity and

Conservation, v.10, n.1, p.79-98, 2001.

JULIÃO, G. R.; AMARAL, M. E. C.; FERNANDES, G. W. Galhas de insetos e suas plantas hospedeiras no Pantanal Sul Mato-grossense. Naturalia, v.27, n.1, p.47-74. 2002.

JULIÃO, G. R. et al. Insetos galhadores associados a duas espécies de plantas invasoras de áreas urbanas e peri-urbanas. Revista Brasileira de Entomologia, v.49, n.1, p.97106, 2005.

LEAL, I. R. Diversidade de formigas em diferentes unidades de paisagem da Caatinga. In: LEAL, I. R.; TABARELLI, M.; SILVA, J. M. C. (Eds.). Ecologia e conservação da caatinga. Recife: Universidade Federal de Pernambuco, 2003. p.435-462.

LEAL, I. R.; TABARELLI, M.; SILVA, J. M. C. Ecologia e conservação da Caatinga. Recife: Universidade Federal de Pernambuco, 2003. 822p.

LEBEL, P.; SILVA, S. C. L.; ALMEIDA-CORTEZ, J. S. Galling insect distribution on Psychotria barbiflora (Rubiaceae) in a fragment of Atlantic Forest. Ecotrópicos, v.21, n.1, p.46-53, 2008.

Revista Árvore, Viçosa-MG, v.36, n.2, p.269-277, 2012
MAIA, V. C. The gall midges (Diptera, Cecidomyiidae) from three restingas of Rio de Janeiro State, Brazil. Revista Brasileira de Zoologia, v.18, n.2, p.583-629, 2001.

MAIA, V. C.; FERNANDES, G. W. Insect galls from Serra de São José (Tiradentes, MG, Brazil). Brazilian Journal of Biology, v.64, n.3, p.423-445, 2004.

MAIA, V. C.; MAGENTA, M. A. G.; MARTINS, S. E. Ocorrência e caracterização de galhas de insetos em áreas de restinga de Bertioga (São Paulo, Brasil). Biota Neotropica, v.8, n.1, p.167-197, 2008.

OLIVEIRA, J. C.; MAIA, V. C. Ocorrência e caracterização de galhas de insetos na restinga de Grumari (Rio de Janeiro, RJ, Brasil). Arquivos do Museu Nacional, v.63, n.4, p.669-675, 2005.

PEREIRA, I. M. et al. Use-history effects on structure and flora of caatinga. Biotropica, v.2, n.35, p.154-165, 2003.

RODAL, M. J. N.; NASCIMENTO, L. M.; MELO, A. L. Composição florística de um trecho de vegetação arbustiva caducifólia, no município de Ibimirim, Pernambuco, Brasil. Acta Botanica Brasílica, v.13, n.1, p.15-28, 1999.

SAMPAIO, E. V. S. B. Overview of the Brazilian caatinga. In: BULLOCK, S. H.; MOONEY, H. A.; MEDINA, E. (Eds.) Seasonal dry tropical forests. Cambridge: Cambridge University Press, 1995. p.35-63.

SAMPAIO, E. V. S. B. Uso das plantas da Caatinga. In: SAMPAIO, E. V. S. B. et al. (Eds.) Vegetação e Flora da Caatinga. Recife: Associação Plantas do Nordeste (APNE) e Centro Nordestino de Informação Sobre Plantas, 2002. p.49-90.

SANTOS-MENDONÇA, I. V. et al. Caracterização e distribuição espacial de galhas em Clusia nemorosa G. Mey (Clusiaceae) em uma área de Floresta Atlântica, Igarassu, PE. Lundiana, v.8, n.1, p.49-52, 2007.

SHORTHOUSE, J. D.; WOOL, D.; RAMAN, A. Gall-inducing insects - Nature's most sophisticated herbivores. Basic and Applied Ecology, v.6, p.407-411, 2005. 
SILVA, S. C. L.; ALMEIDA-CORTEZ, J. S. Galhas entomógenas de Miconia prasina (Sw.) DC (Melastomataceae) em remanescentes de Floresta Atlântica Nordestina. Lundiana, v.7, n.1, p.33-37, 2006.

SILVA, G. C.; SAMPAIO, E. V. S. B. Biomassas de partes aéreas em plantas da Caatinga. Revista Árvore, v.32, n.3, p.567-575, 2008.
STRONG, D. R.; LAWTON, J. H.; SOUTHWOOD, T. R. E. Insect on plantscommunity patterns and mechanism. Cambridge: Massachusetts Harvard University 1984. p.313.

ZAR, J. H. Biostatistical analysis.

Englewood Cliffs: Prentice-Hall, 1996. 929p. 
